\title{
GÊNEROS TEXTUAIS NA INTERNET: UMA EXPERIÊNCIA DE EDUCAÇÃO PELA PESQUISA
}

\section{Ana Lúcia Sarmento Henrique}

Professora de Leitura e Produção de Texto do CEFET-RN; Doutoranda em Educação. analucia@cefetrn.br

Recebido em agosto/2004 e Aceito em Outubro 2004

\section{RESUMO}

Este artigo descreve uma experiência de educação pela pesquisa implementada no CEFETRN. Fundamenta-se em Demo (2000), para quem ensinar através da pesquisa é ensinar um posicionamento reflexivo, crítico, reconstrutivo e inovador; e em Echeverría (2002), que defende que ensinar por meio da pesquisa é ensinar em valores científicos. Propôs-se à turma a preparação de um artigo. Para sua consecução, a classe foi dividida em grupos. Cada um selecionou um gênero textual encontrado na Internet. Foram distribuídos dois roteiros, realizaram-se encontros em sala para discussão do progresso das pesquisas, cujo resultado foi apresentado em forma de seminário aberto à comunidade. O processo não foi isento de dificuldades, mas os pontos positivos prevaleceram: a integração dos conteúdos da disciplina em uma atividade prática, a construção de conhecimento novo resultante de análise e reflexão; e a reflexão sobre fenômenos cotidianos, para provocar o estranhamento e conseqüente ad-miração daquilo que já se tornou habitual.

Palavras-chave: educação, pesquisa, valores científicos, gêneros textuais.

\section{GÉNEROS TEXTUALES EN INTERNET: UNA EXPERIENCIA DE EDUCACIÓN POR INTERMEDIO DE LA INVESTIGACIÓN}

\section{RESUMEN}

Este artículo describe una experiencia de educación por intermedio de la investigación instituida en el CEFET-RN. Fundamenta-se en Demo (2000), para quien educar por medio de la investigación es formar una actitud reflexiva, crítica, reconstructiva e innovadora. También se apoya en Echeverría (2002) que aboga que enseñar por medio de la investigación es educar en valores científicos. Se propuso a los alumnos la producción de un artículo científico para el que se los agrupó en equipos más pequeños. Cada grupo eligió un género textual de Internet. Se distribuyó dos guiones, se realizaron encuentros en aula para discutir el progreso de las investigaciones, cuyos resultados fueron presentados en coloquio abierto a la comunidad. Los puntos positivos sobrepasaron las dificultades: la integración de los contenidos de la disciplina en una actividad práctica, la construcción de conocimiento como resultado de análisis e reflexión, y la reflexión sobre fenómenos habituales a fin de provocar la ad-miración de lo que es ya corriente.

Palabras-llave: educación, investigación, valores científicos, géneros textuales. 


\section{GÊNEROS TEXTUAIS NA INTERNET: UMA EXPERIÊNCIA DE EDUCAÇÃO PELA PESQUISA}

\section{INTRODUÇÃO}

Este artigo descreve uma experiência de educação pela pesquisa implementada no Centro Federal de Educação Tecnológica do Rio Grande do Norte - CEFET-RN, na turma 2.71.02 de Tecnólogos em Desenvolvimento de Software, do turno noturno, no primeiro semestre de 2004. O trabalho de educação pela pesquisa, que tem como base teórica Demo (2000) e Echeverría (2002), ocorreu como parte das atividades e conteúdos programados para a disciplina de Leitura e Produção de Texto 1. Os alunos foram solicitados a escrever um artigo científico sobre gêneros textuais que circulam na Internet, um tema cotidiano para tecnólogos da área. Mais que apenas escrever, eles vivenciaram, de forma orientada, o processo de pesquisa que resultou em um trabalho científico com o objetivo não de educar cientistas, mas de formar indivíduos nos valores que regem o fazer científico. Dito de outra maneira, não era objetivo do projeto formar para a ciência, mas formar pela ciência.

$\mathrm{Na}$ exposição deste artigo, optou-se por relatar o processo vivenciado, apresentando sempre que possível as impressões pessoais a respeito da experiência. Dessa forma, a subjetividade, muitas vezes latente em um trabalho científico, neste é indissociável de sua estrutura mesma. Como partícipe da experiência, meu envolvimento foi inevitável e isso está expresso nas marcas lingüísticas que indicam que eu vivi com meus alunos o processo de formação pela ciência.

O artigo está dividido em 5 seções. Na primeira, focalizamos a fundamentação teórica, justificando a escolha dessa atividade como parte do processo de formação de um tecnólogo. Em seguida, fazemos uma breve descrição do grupo de trabalho, para, na terceira seção, apresentar os instrumentos facultados aos alunos e fazer uma avaliação do processo. Numa quarta seção, fazemos um breve resumo de cada trabalho apresentado pelos grupos, para, posteriormente, apresentar nossas últimas reflexões sobre a experiência.

\section{JUSTIFICATIVA TEÓRICA}

A proposta de trabalho se fundamenta teoricamente em Demo (2000) e em Echeverría (2002). O educador brasileiro afirma que o diferencial da educação pela pesquisa "é o questionamento reconstrutivo, que engloba teoria e prática, qualidade formal, política, inovação e ética.” (DEMO, 2000, p.1). Não se trata de formar pesquisadores profissionais, mas de interiorizar um comportamento crítico e criativo. Echeverría (2002), filósofo espanhol, vai mais longe e afirma que a educação pelo fazer científico é, acima de tudo, uma educação em valores científicos, é muito mais que passar informações ou transmitir conhecimentos. É, sobretudo, formar comportamentos indagadores, investigativos, que se pautam pela busca de respostas, que não se contentam com o estabelecido, mas que estranham e refletem sobre esse status quo. É educar não apenas para o fazer científico, mas educar para que, em suas vidas profissionais, os valores epistemológicos que regem a pesquisa científica - verdade, precisão, ponderação, rigor, explicitude, coerência, responsabilidade, ética profissional, capacidade de generalização, de síntese e de análise, criatividade, habilidade para trabalhar em grupo - façam também parte de suas ações. De uma certa maneira, este pensamento vem ao encontro do conceito cabeça bem feita, de Edgar Morin (2001). Para o pensador francês, a cabeça bem feita, que se opõe à cabeça cheia, é aquela que, mais que acumular saberes, sabe interligá-los e dar-lhes sentido, sabe 
colocar e resolver problemas. Para formar uma cabeça bem feita, continua Morin, deve-se incentivar a curiosidade, a atitude interrogativa, desenvolver o exercício da dúvida, o bom uso da lógica, da dedução, da indução, a arte da argumentação e da discussão. "Compreende também a previsão, a flexibilidade de espírito, a argúcia, a atenção vigilante e o sentido de oportunidade e a arte de transformar os detalhes aparentemente insignificantes em indícios que permitam reconstruir toda uma história "(MORIN, 2001, p.27).

O título desse artigo já revela as duas preocupações básicas que fundamentaram a proposição de um trabalho de pesquisa para o curso de Tecnólogos em Desenvolvimento de Software: a integração do conteúdo ministrado em sala de aula e a experiência mesma do fazer científico. Por isso, têm-se, de uma parte, os objetivos da pesquisa no curso e, de outro, os objetivos relativos à formação de um comportamento preliminar científico. Em virtude dessa duplicidade de intenções, o trabalho proposto para a turma apresenta dois grupos de objetivos: um que se refere à prática de uma investigação científica e outros mais específicos do curso, que, no entanto, não estão desvinculados dos anteriores. Aos primeiros chamei de objetivos propedêuticos, pois dizem respeito à formação de um comportamento fundamentado no fazer científico; aos segundos, de objetivos do curso, já que estão mais ligados aos conteúdos ministrados em sala de aula. No entanto, é importante ressaltar que todo o programa elaborado para o curso está ligado à produção e leitura de textos técnicos e científicos.

Os objetivos propedêuticos, de iniciação científica, de formação de um comportamento investigativo são:

a) Incentivar o comportamento questionador, investigativo e crítico;

b) Incentivar a reflexão sistemática como processo de construção do conhecimento;

c) Fazer o aluno construtor de um conhecimento novo;

d) Tornar o aluno sujeito da construção de seu conhecimento.

Como objetivos do trabalho no curso, propusemos:

a) Pesquisar as novas formas lingüísticas que estão surgindo como conseqüência do advento da Internet e do computador como meio de comunicação;

b) Desenvolver uma atitude investigativa característica do fazer científico;

c) Produzir um artigo científico;

d) Integrar, em um artigo científico, todo o conteúdo programático estudado ao longo do curso na disciplina Leitura e Produção de Textos 1; e

e) Utilizar a variante lingüística oral em uma situação de formalidade.

Com a consecução desses objetivos, pretende-se que o aluno perceba que não é mero objeto reprodutor de um conhecimento já existente, espera-se que ele seja crítico a respeito desse conhecimento, ao mesmo tempo em que se sinta capaz de produzir conhecimento novo; pretende-se que o discente ad-mire ${ }^{1}$ seu cotidiano e perceba a importância para a sua própria formação de um comportamento questionador, uma atenção vigilante. Mais do que ter a cabeça cheia de informações, ele precisa ter a cabeça bem feita (MORIN, 2001), pronta para interligar os conhecimentos, analisá-los, sintetizá-los e aplicá-los na resolução de problemas.

\footnotetext{
${ }^{1}$ Ad-mirar aqui está tomado em seu sentido filosófico ou seja, é uma ação humana conseqüente da ponderação que se faz mediante umna racionalidade valorativa.
} 


\section{O GRUPO DE TRABALHO}

Esse trabalho de educação pela pesquisa foi desenvolvido na turma 2.71.02 de Tecnólogos em Desenvolvimento de Software, do turno noturno, no período de março a julho de 2004. Inicialmente a turma era composta por cerca de 30 (trinta) alunos, mas ao longo do semestre, por motivos variados, alguns desistiram. Terminamos o curso com 26 alunos. Desses 26, 22 responderam a um questionário elaborado para obter-se o perfil do grupo.

A idade do grupo variou entre 18 e 48 anos, concentrando-se principalmente entre 19 e 24 anos. Do total pesquisado, 17 são do sexo masculino e 5 são do sexo feminino. Todos têm outra atividade no período diurno: 13 estudam em outras instituições - 12 na Universidade Federal do Rio Grande do Norte e um na Universidade Potiguar - e os 9 restantes trabalham - no Exército, Banco do Brasil, Prefeitura, UFRN, Tribunal de Contas e em empresas de programação. Entre os alunos da turma, 7 estudaram no CEFET-RN Serviços (1), Eletromecânica (2), Geologia e Mineração (1), Construção Civil (2) e Tecnologia em Desenvolvimento de Software (1) - e 14 vêm de outros estabelecimentos de ensino.

\section{METODOLOGIA ADOTADA}

No primeiro dia de aula, 11 de março, junto com a explicitação do programa, expôs-se a proposta de atividade de pesquisa. A turma foi dividida em grupos de 4 (quatro) pessoas. Cada um se encarregou de pesquisar, a sua escolha, um gênero textual encontrado nas interações via computador. Cada grupo selecionou um corpus de trabalho, cujas cópias me foram entregues, para que eu pudesse acompanhar e orientar a pesquisa.

Os encontros de orientação, apesar de estarem previstos para momentos extraclasse, ocorreram nos horários de aula, uma vez que todos os alunos têm atividades no turno diurno. Para isso, houve necessidade de se fazerem alguns ajustes no conteúdo programado para o semestre a fim de se adequar a quantidade de horas-aula disponíveis ao que se propunha fazer. Além disso, nesses momentos de orientação, houve necessidade de dividir a turma em dois grandes grupos para poder dedicar 20 minutos de orientação a cada um deles.

Para a orientação da análise elaboraram-se dois instrumentos (Figuras 1 e 2 ) que foram entregues aos alunos para que eles admirassem o corpus, tendo como base algumas questões pertinentes ao fazer científico. $\mathrm{O}$ primeiro roteiro está dedicado ao fazer inicial de uma pesquisa científica: delimitação do tema, levantamento de hipóteses, escolha da metodologia de trabalho e descrição do corpus.

O segundo, que pressupunha um estágio mais

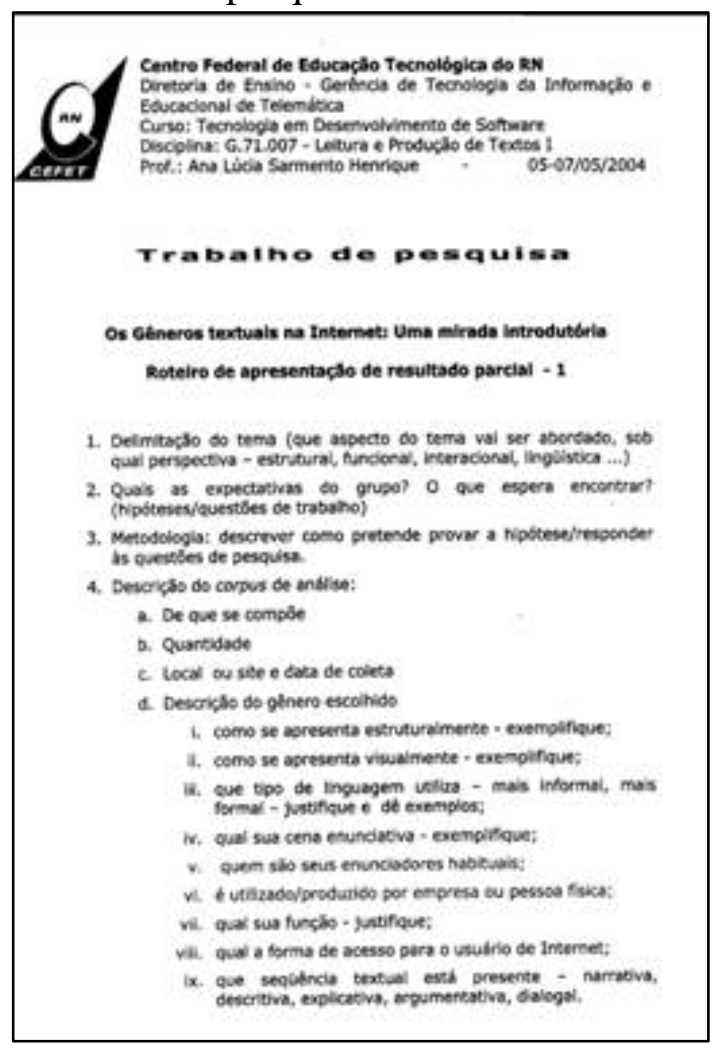

Figura 1: Roteiro de apresentação de resultado parcial 1. 


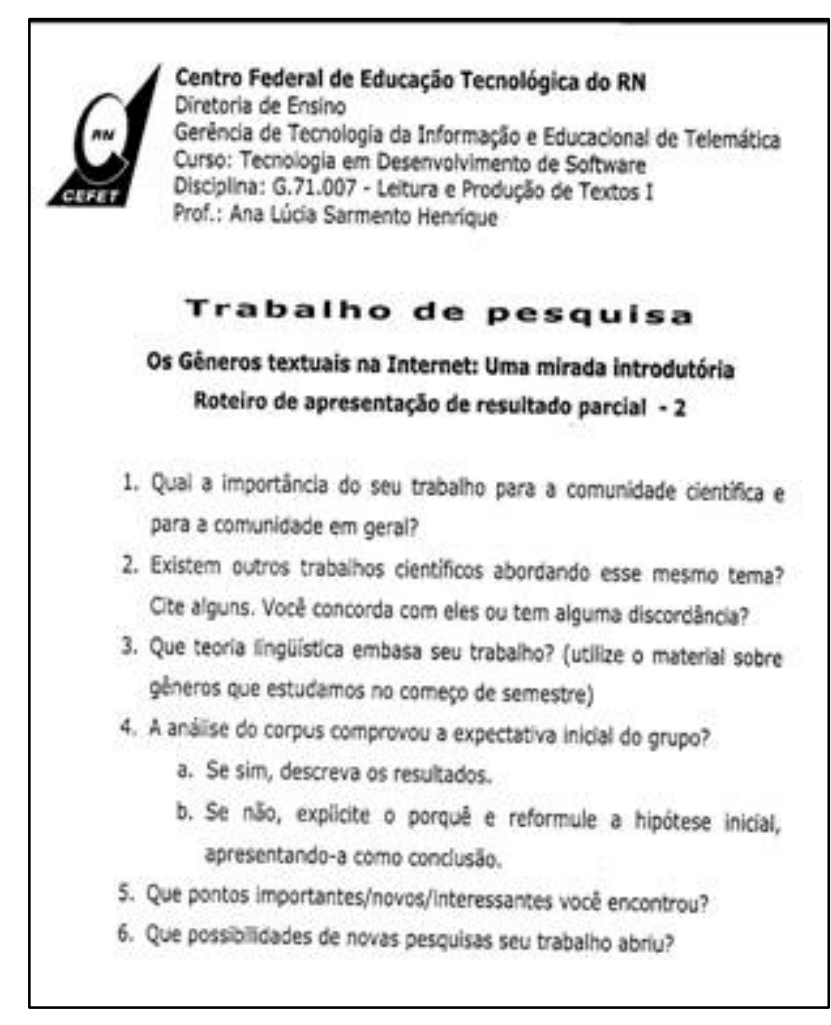

Figura 2: Roteiro de apresentação parcial 2. aprofundado do trabalho de pesquisa, orienta para a reflexão sobre o que se havia escrito, a partir do roteiro 1 e a escritura das conclusões.

Além desse material de orientação sobre a pesquisa em si, como se levantou a possibilidade de se publicar a experiência junto com os artigos, foram distribuídas normas para a escritura do artigo científico, seguindo as exigências da Revista Holos para envio de trabalhos, e da ABNT para citações internas e para as referências bibliográficas. É importante assinalar que a estruturação do artigo científico, suas características e funções assim como os modos de citar o discurso alheio em um texto científico são parte de nosso conteúdo programático. Pensamos que com esses instrumentos o aluno estaria munido de recursos e conhecimentos necessários para a produção final exigida.

\section{AVALIAÇÃO DO PROCESSO}

A prática nem sempre transcorre como se planeja na teoria. Vejamos os percalços. O primeiro problema foi a pouca disponibilidade de tempo dos alunos, pois como foi explicitado no item o grupo de trabalho, todos tinham atividades nos períodos matutino e vespertino. Isso levou à necessidade de se fazer a orientação do trabalho nos horários de aulas e, para tornar isso factível, a turma foi dividida em dois grandes grupos que viriam de forma alternada às aulas específicas de orientação: três grupos em um dia e quatro em outro. Como todos professores sabemos, a prática de trabalho em grupo entre os alunos é geralmente a de dividir as tarefas e cada um se ocupa de uma parte. Com esse grupo não foi diferente. Tal atitude gerou descompasso no andamento da pesquisa uma vez que nunca estavam todos os membros do grupo nas aulas de orientação. No entanto, vale salientar que esse descompasso, foi, de certa forma, compensado no período final dedicado à produção do artigo e das apresentações.

Outro problema foi a pouca experiência dos alunos com o processo de pesquisa. Eles, então, não estavam conscientes das idas e vindas próprias do fazer científico, o exercício da dúvida lhes deixava inseguros, desesperados; buscavam respostas prontas e imediatas e quando se levantava ou se apresentava uma nova possibilidade, mais insegurança surgia. Parece que lidar com a incerteza do processo de busca e com a construção do novo foi angustiante para vários deles.

Outro elemento dificultador foi a incipiência do tema como fonte de pesquisa. As buscas sobre investigações afins resultaram, em geral, infrutíferas. No entanto, esse ponto negativo, transformou-se, na realidade, em positivo, uma vez que as conclusões a que os 
alunos chegaram foram fruto de análise e representam uma contribuição inovadora à pesquisa lingüística. Em nossa pesquisa bibliográfica, a grande maioria dos trabalhos encontrados diz respeito ao hipertexto de forma mais geral, esquecendo os gêneros hipertextuais como objeto de investigação.

Alguns títulos localizados nas nossas pesquisas confirmam essa afirmativa: História do hipertexto, de Otávio Filho e Egnaldo Pelegrino, disponível em <http:/www.facom/ufba.br/hipertexto/história.html>; ou o clássico Hypertext. The eletronic labyrinth ,de Ilana Snyder; e a tese doutoral de Maria Helena Pereira Dias Hipertexto - o labirinto eletrônico: uma experiência hipertextual. Outro autor que aborda o assunto, e é citado por quase todos os que pesquisam o tema, é Pierre Levy e seu livro As tecnologias da inteligência: o futuro do pensamento na era da informática. Além desses, outros lingüistas brasileiros seguem o mesmo caminho: Ingedore Vilaça com Texto e hipertexto, capítulo do livro Desvendando os segredos do texto, e Marcuschi com o Linearização, cognição e referência. O desafio do intertexto são exemplos dessa tendência. Entretanto, apesar dos percalços, no cômputo final, a experiência foi positiva. Cito três pontos que me pareceram mais relevantes para justificar essa afirmativa. O primeiro deles foi a integração dos conteúdos da disciplina em uma atividade prática. A escritura do artigo revelou que o grupo havia compreendido e sabia utilizar os conteúdos ministrados em sala, desde as formas de citar o discurso alheio, à citação de referências bibliográficas seguindo as normas da ABNT, e à elaboração do resumo, sem esquecer a progressão discursiva no texto escrito, a adequação da linguagem ao texto científico com o uso da impessoalização e a preocupação com a norma culta. Dessa forma, os conteúdos teóricos revestiram-se de sentido prático. Essa questão também foi sentida pelos alunos, uma vez que, em resposta à questão sobre a pertinência entre o conteúdo ministrado em sala e as exigências do trabalho final, de 22 respondentes, 19 disseram que havia pertinência, 2 afirmaram que houve uma coerência regular e apenas um respondeu que não havia pertinência.

Outro dado bastante positivo foi a construção de um conhecimento novo resultado de análise e reflexão. Vivenciar a incerteza do processo do fazer científico pode ter sido angustiante para alguns deles, mas os grupos em sua maioria ficaram satisfeitos - e eu poderia arriscar-me a dizer orgulhosos - com o seu trabalho final. Conforme já observamos anteriormente neste artigo, devido à incipiência do tema como objeto de pesquisa, pode-se afirmar que as análises e resultados a que se chegou nos grupos são realmente contribuições novas ao conhecimento sobre gêneros hipertextuais.

Ainda vale lembrar um item importante: a atitude de reflexão sobre fenômenos do cotidiano de cada um deles. Todos, por estudarem no curso de Tecnologia em Desenvolvimento de Software, têm como corriqueiros os vários gêneros que circulam no meio eletrônico e não estão acostumados a refletir sobre eles. São meros receptores passivos do que existe na Internet. A atitude de ad-miração lhes é estranha. A prática do processo de produção do conhecimento científico levou-os ao estranhamento daquilo que lhes é habitual e que lhes passa desapercebido, levou-os a observar e analisar "os detalhes aparentemente insignificantes" dos gêneros do dia-a-dia de cada um para transformar esses detalhes em indícios que puderam permitir a construção de uma outra história.

Um quarto tópico positivo na experiência vivenciada foi a qualidade dos artigos escritos. Isso pode ser comprovado no item a seguir que traz um resumo de cada artigo. Os trabalhos apresentaram conteúdos inovadores, acrescentaram conhecimento novo ao edifício do conhecimento. Além disso, os alunos foram sujeitos agentes nessa construção. 
Nada estava pronto, houve a angústia do início, a incerteza do processo e um porto (in)seguro: o artigo. Na verdade, para aquilo que se tinha em mente ao propor o trabalho, a vivência do fazer científico era tão ou mais importante que sua materialização em um trabalho final de curso.

Em relação à estruturação, no geral, os artigos apresentaram-se conforme as normas distribuídas para sua produção e segundo a estrutura do gênero artigo científico, utilizando os padrões lingüísticos da norma culta exigida para um trabalho dessa natureza.

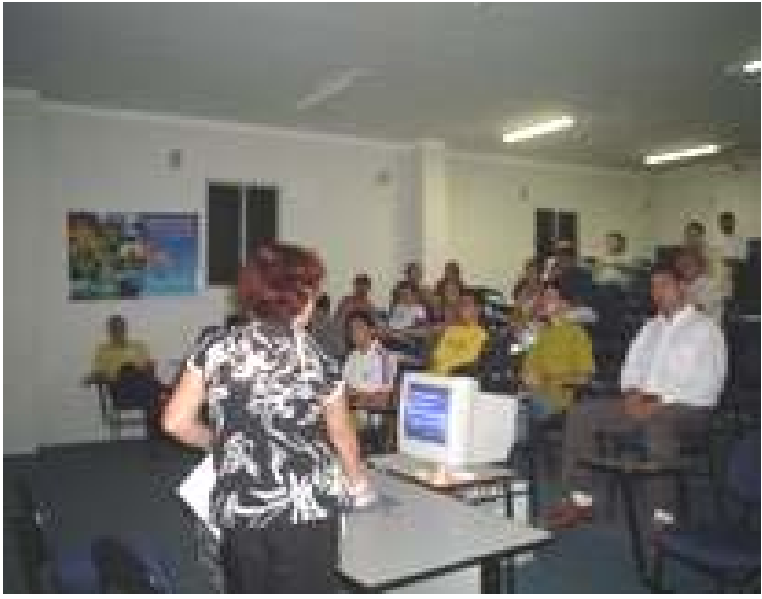

Figura 3: Seminário sobre Gêneros Textuais na Internet
No entanto, entre todos os itens, vale ressaltar a apresentação oral em seminário aberto à comunidade. Para a preparação dessa atividade, reservamos as últimas duas semanas do semestre letivo. Um dos alunos, Arthur Ronald, criou o cartaz que foi afixado nas dependências da Instituição, abrimos inscrições e, no dia, contamos com a presença, não só de professores, servidores e alunos, mas também de algumas pessoas externas à comunidade cefetiana. O momento era de expectativa para todos: para os alunos que apresentariam o resultado de um semestre letivo de trabalho e para mim como orientadora de todos eles.

Aproveitando seus conhecimentos na área da informática, todos os grupos prepararam material de apoio de excelente qualidade, e, apesar do nervosismo, natural nesses momentos, as exposições foram claras, diretas, objetivas e refletiram bastante bem os resultados apresentados no trabalho escrito.

Para que se possa fazer uma idéia do resultado a que se chegou, apresento, a seguir, um pequeno resumo de cada um dos sete artigos e os atores responsáveis pela sua construção.

\section{RESUMO DOS TRABALHOS DOS ALUNOS}

O primeiro grupo a se apresentar estava composto por Diego Carvalho, Eduardo Andrez, Leandro Pinheiro e Thiago Trigueiro. Seu trabalho tinha como título IRC - bate-papo virtual e analisou a interação no bate-papo de IRC, comparando-a entre usuários de dois canais distintos, o Canal Natal e o Canal CEFET. Para tal, os alunos selecionaram algumas categorias de análise, tais como: o flood, que trata do ruído na comunicação provocado pela repetição exagerada de linhas; o público ao qual se destina o canal; a forma como ocorre o

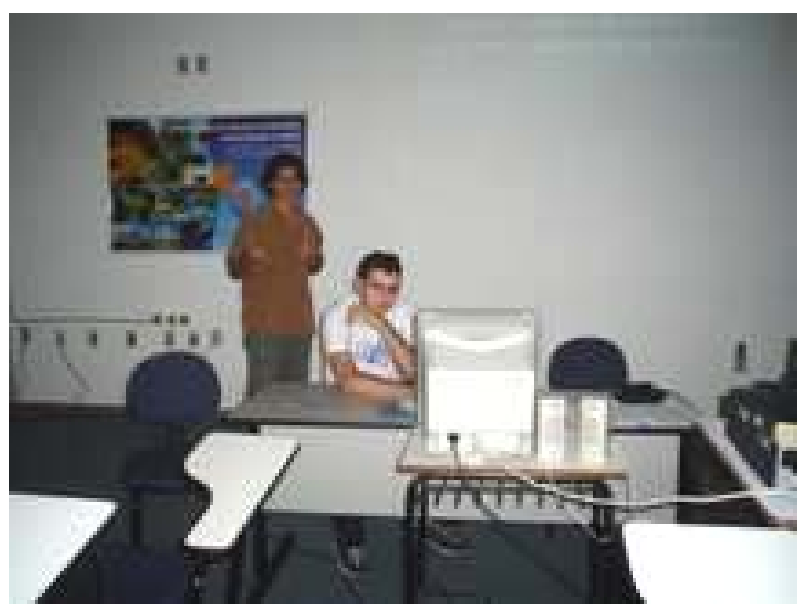

Figura 4: IRC - Bate-papo virtual 
diálogo entre os usuários de cada canal; e a quantidade de pessoas que utilizam tais canais, na tentativa de mostrar como essas categorias influenciam a interação entre os usuários. Concluíram que a interação acontece de forma diferenciada em cada um dos canais e que isso interfere na estrutura lingüística visualizada no IRC.

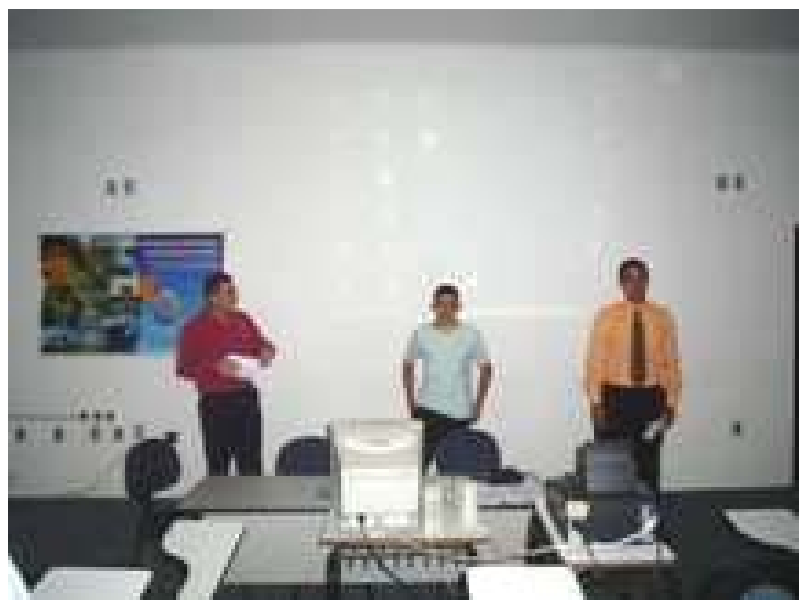

Figura 5: Charge - Uma nova forma de utilização

O segundo grupo era formado por Thiago de Carvalho, Arthur Emanuel, Artur Ronald e Rômulo Augusto. A comunicação titulada charge. Uma nova forma de utilização analisou a charge eletrônica fazendo um percurso histórico sobre as formas da charge desde o seu surgimento no mundo e no Brasil. Além disso, comparou esse gênero com o cartum e com as histórias em quadrinhos para concluir que, apesar de existirem na rede as charges convencionais, sem movimento ou som, na Internet, ele ganhou uma nova roupagem herdada das histórias em quadrinhos, porém só possibilitada pelos recursos das novas tecnologias. Os autores sugeriram, em sua conclusão, um nome para esse gênero nascente: charge animada, charqs ou charge em quadrinhos.

O terceiro trabalho, Os gêneros textuais na Internet: hipertexto e publicidade, foi apresentado por Bárbara Cristiany, Cláudio Cavalcante, Fabrício Freire e Thiago Lucena. O interesse central foi apresentar o uso de técnicas de hipertexto associadas a características multimídia para construção de ambientes publicitários para a Internet. Nessa perspectiva, eles optaram por analisar materiais que se caracterizam por incluir o uso de anúncios publicitários em formato de banner e pop-up, além das páginas comerciais. Eles compararam a publicidade realizada na Internet com

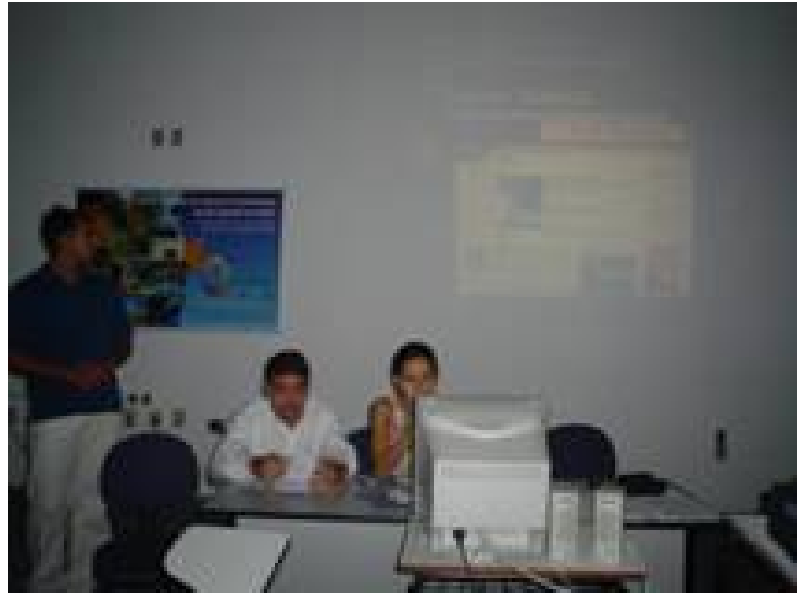

Figura 6: Os gêneros textuais na Internet - Hipertexto e publicidade. outros tipos de publicidade realizada pelas demais mídias e analisaram a utilidade da propaganda on-line, apontando suas vantagens e desvantagens, levando em consideração o usuário e os novos desafios da publicidade interativa. Concluíram que a publicidade hipertextual deve ser utilizada com parcimônia, uma vez que seu excesso torna poluída a sua visualização e o resultado pode ser contrário ao pretendido.

Em seguida, apresentou-se o grupo composto por Carlos Bernardino, Endrigo Stefanes, Érico Renato e Jefferson Freire, com a comunicação Blog: o porquê da sua importância. No trabalho, além de discutir a existência, definição e características do blog, faz-se uma relação entre ele e o gênero textual diário, através da observação de suas semelhanças e 
diferenças estruturais. Entre as características comuns, eles afirmam que ambos apresentam-se datados, relatam fatos do cotidiano, é freqüente o uso de verbos na primeira pessoa, no presente ou passado e o uso de uma linguagem informal e espontânea. No entanto, para adequar-se ao novo meio e às novas necessidades, esse gênero contemporâneo apresenta algumas divergências em relação a seu ancestral, por exemplo, já não é privativo, está potencialmente disponível para qualquer um que acesse a Internet; suas informações são divulgadas em tempo real e existe a possibilidade de

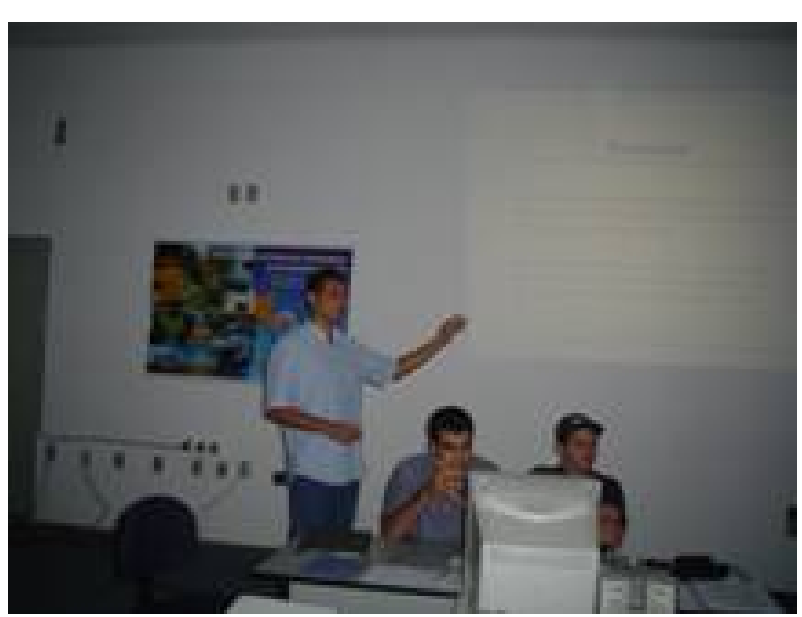

Figura 7: Blog - o porquê da sua importância

blogs comunitários, fato impensável relativamente aos diários tradicionais.

O Grupo de Caroline Silva, Gustavo Henrique e Vielimir Silva apresentou-se em seguida com uma pesquisa comparativa entre o jornal eletrônico e o jornal impresso. Eles fizeram um estudo de caso com uma edição de jornal veiculada pelas duas mídias em um mesmo dia. Pelo título, Jornal eletrônico e jornal impresso: diferenças entre as duas mídias percebe-se que ambos foram considerados mídia pelo grupo, pois, para eles, não foi possível enquadrá-los em nenhum gênero textual específico.

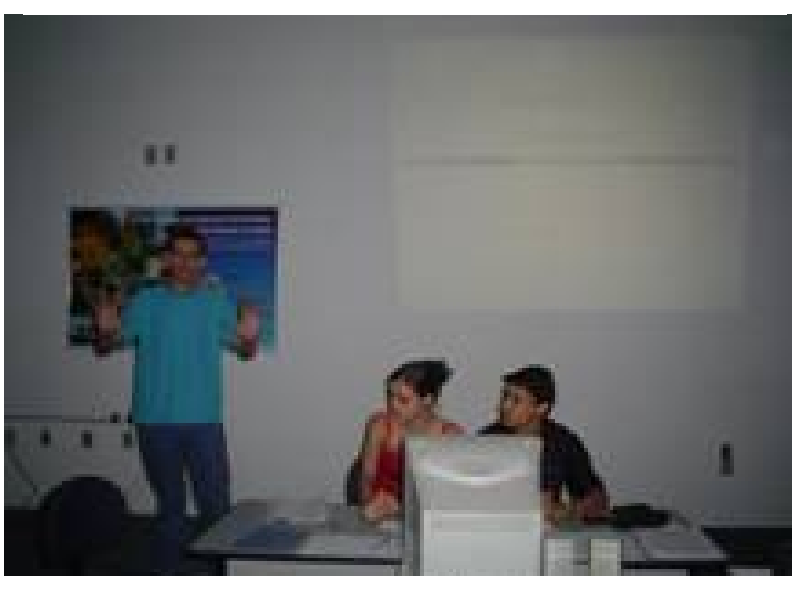

Figura 8: Jornal eletrônico e jornal impresso: diferenças entre as duas mídias

Mas é, na verdade, uma reunião de vários gêneros textuais e isso possibilita a transmissão de informações de maneira completa e variada. Sobre as duas mídias, afirmam que trazem

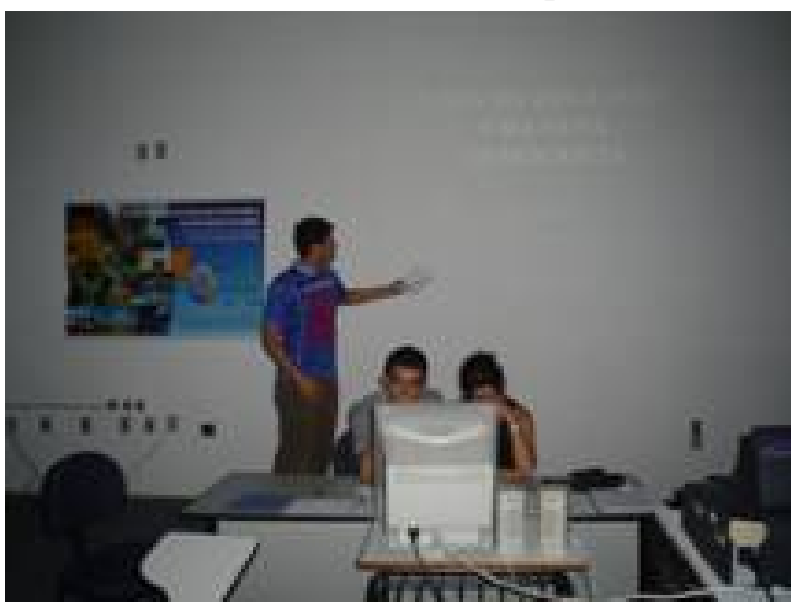

Figura 9: Lista de Discussão: uma nova democracia. praticamente a mesma carga informativa e que não se pode pensar que o jornal eletrônico substituirá o jornal impresso, devido à exclusão tecnológica e à rejeição de membros da sociedade aos objetos virtuais.

O Penúltimo grupo a se apresentar no seminário era composto por Michele Furtado, Liza Gabrielle, Pedro Victor e Victor Hugo Fernandes. O artigo, titulado Lista de Discussão: uma nova democracia, apresentou uma análise sobre esse gênero textual na Internet, focalizando seu aspecto funcional e estrutural por meio da lista "DEBIANCE”, uma distribuição do Linux, um 
sistema operacional livre. Para o estudo, apoiaram-se na definição de gênero textual de MARCUSCHI (2002), mais precisamente na concepção sócio-histórica expressa no texto Gêneros Textuais: definição e funcionalidade. Eles avaliaram a questão estrutural da lista de discussão, comparando-a com a estrutura do e-mail e do chat. Concluíram que a lista apresenta características estruturais desses dois gêneros, que tem a dinâmica do chat e, para escrever, o espaço disponível do e-mail. Isso o torna um bom meio de comunicação, que pode ser caracterizado como um sub-gênero do correio eletrônico.

A última comunicação foi apresentada por Ivanilson Júnior e Luis Tadeu e abordou o tema da comunicação interna na empresa, via rede interna. Com o título Correspondência eletrônica interna: impacto na produtividade, o grupo buscou detectar o papel da comunicação interna para o desenvolvimento e melhoria da organização. Dentre as formas de comunicação pesquisadas, deuse ênfase ao correio eletrônico. Mais especificamente, eles analisaram 3 tipos de correspondência interna com graus diferentes de formalidade a fim de perceber sua influência na produtividade

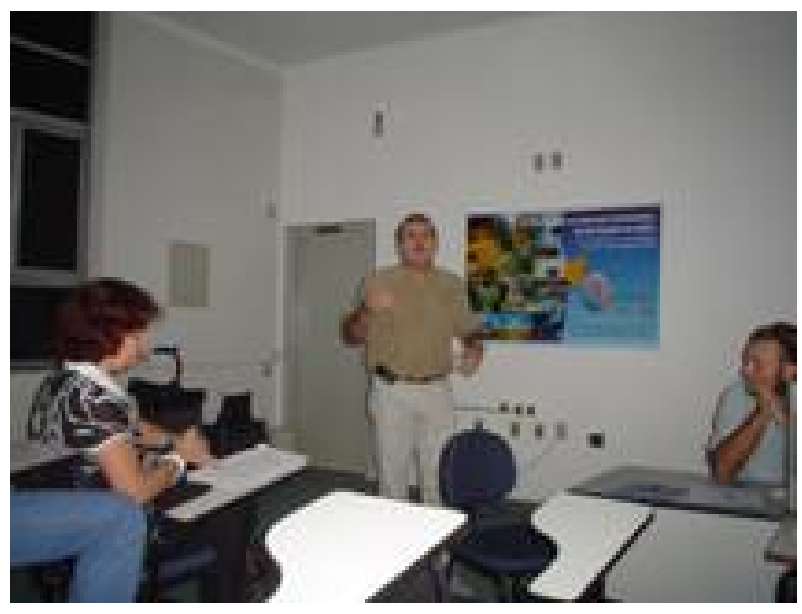

Figura 10: Correspondência eletrônica interna: impacto na produtividade da empresa. Perceberam que a intranet permite a fusão entre formalidade e informalidade, pois, sobre o mesmo tema, circulam emails formais e informais, e concluíram que essa prática tem impacto positivo na produtividade.

\section{CONCLUSÕES}

Todos os objetivos discriminados neste artigo, sejam propedêuticos ou relativos ao conteúdo programático, convergem para um único ponto: a formação do aluno, através da experiência do fazer científico, como sujeito de sua aprendizagem e sujeito consciente de que pode ser partícipe na construção do edifício do conhecimento. Uma experiência é formadora quando dela o sujeito sai transformado, quando, ao experienciar, ele sai outro, embora, paradoxalmente, permaneça o mesmo. A experiência de formação a partir dos dados do cotidiano permite ao indivíduo que ele encare essa sua realidade que lhe é habitual com outros olhos. A utopia que mobilizou a implementação desse projeto é exatamente essa, a de que ele tenha sido para os alunos, como foi para mim, uma experiência. Uma experiência que lhes tenha permitido vivenciar e talvez internalizar os valores epistemológicos que regem a pesquisa científica, - verdade, precisão, ponderação, rigor, explicitude, coerência, responsabilidade, ética profissional, capacidade de generalização, de síntese e de análise, criatividade, habilidade para trabalhar em grupo para que possam eles utilizá-los em sua vida profissional.

\section{REFERÊNICAS BIBLIOGRÁFICAS}

DEMO, P. Educar pela pesquisa. 4.ed. São Paulo : Autores Associados, 2000. ECHEVERRÍA, J. Ciencia e Valores. Barcelona : Destino. 2002.

MORIN, E. La mente bien ordenada: repensar a reforma. Reformar o pensamento. 2.ed. Barcelona: Seix Barral. 2001. 